\title{
REFLEXIONES SOBRE LAS ESTROFAS 112 Y 113 DEL LIBRO DEL ARCIPRESTE
}

JOSÉ JURADO

Carleton University. Ottawa

Los pasajes en cuestión corresponden 'a la rúbrica «De cómo todas las cosas del mundo son vanidat...». Y los puntos que me propongo comentar en el presente trabajo son los que siguen por orden de verso (los textos presentados se toman de la edición de A. Blecua, Madrid, Cátedra, 1992):

E yo, como estava solo, sin conpañía, codiçiava tener lo que otro para sí tenía: puse el ojo en otra, non santa mas sentía; yo cruziava por ella, otro la avié valdia.

estr. 112

Reconsideremos una vez más el problema que plantea el v. $112 \mathrm{c}$ con la voz sentia. Cejador la entendió como verbo, referido al yo parlante (112a), lo cual le forzó a interpretar mas como adverbio y a disociar ambos términos de los previos del verso: ...non santa; más sentía, entendido ello, según él, como 'todavía pensaba y juzgaba más'. M. R. Lida rompió con tal idea y sugirió la enmienda sandia ${ }^{1}$, recibida con aplauso por Morreale ${ }^{2}$ y Corominas, quien a la vez desestimó también la propuesta de J. M. Aguado de sentia/santia 'santificada', por ser voz inexistente en la lengua. $Y$, desde el ya lejano aludido artículo, sandia viene incorporándose al texto ruiciano de las ediciones académicas del $L B A$, salvo en la de Blecua, que deja el texto sin aclarar con la nota de que «se desconoce la acepción de sentia...». Si el texto realmente precisara rectificación, habría sido la de Lida conjetura

\footnotetext{
1 "Notas para la interpretación, influencia, fuentes y texto del "Libro de Buen Amor»", $R F H, 2,1940$, pág. 128 .

2 "Apuntes para un comentario literal del Libro de Buen Amon, BRAE, 43, 1963, pág. 249. M. Morreale, en el mismo lugar citado, sugirió también -creo, con poca fírmeza- la idea de que el mas del verso pudiera ser deturpación de un hipotético mal.
}

$R F E$, LXXXII, $2002,3 .^{\circ}-4^{\circ}$, págs. $397-405$ 
interesante, tanto por la adecuidad del sentido de la voz en el contexto en el que se encaja (de hecho Juan del Encina nos lo confirma: «con qué remedio guarece el que está de amor sandío?» ${ }^{3}$ ), cuanto por el aspecto rítmico de la misma, puesto que el trisilabismo de la forma está asegurado por la rima en el $L B A$ y, repetidamente, en otras poesías medievales:

entiendo que me tienes por loco e sendío, que non traio consejo e ando en radío.

Milagros, $646 \mathrm{bc}$.

...falló çafir culpado, mejor omne non vio; espantóse el gallo, dixo como sandío:...

$$
L B A, 1387 \mathrm{~cd}
$$

por que me llamo sandío

e fago vida sandia,

de tan esquivo cativo

loco es quien se cativa

Canc. Baena, 144: 5-8.

Las deficiencias que me parece advertir en tal conjetura son: $1^{\circ}$. La elección de forma. Dado que el vocablo presenta, desde sus origenes, la alternancia bimembre sendio/sandio (con acentuación prosódica variada: ya sobre la sílaba - $d i$-, ya sobre sen-/san-), hubiera sido más lógico el haber respetado de la lección recibida su primera sílaba sen-, como se presenta en $L B A$ Fontanals-Pons. Si Lida - como parece- no recordó la existencia de la alternancia sendia al proponer su idea, puesto que la tal variante en el $L B A$ la atribuye a deformación jocosa goliarda, Corominas que la comenta ampliamente en su $D C E$ (IV, 136a-39a) y otros editores sucesivos deberían de haber optado por la incorporación al texto de sendia, ya que tal alternancia es la más cercana formalmente a lo que consta en el ms. $S$, el único que presenta el pasaje en cuestión ${ }^{4} .2^{\circ}$. La desconsideración de la consonante -t- de la lección manuscrita: al fijar sandia en el locus (incluso en su forma más consecuente, sendia) se aporta con ello una significa-

\footnotetext{
${ }^{3}$ Obras Completas, ed. Ana M. Rambaldo, t. III, Madrid, Espasa-Calpe, 1978, pág. 376, poema CCXX.

${ }^{4}$ Corominas en su comentario al locus muestra estar convencido de que la forma sendia está «empleada aquí [i.e., en este locus del ms. S] (aunque no en el arquetipo, pero quizá en alguno de los mss. derivados)", ed. $L B A, 1967$, pág. 102. Tal vez el editor basara su negativa en el hecho de que los cuatro casos restantes de la voz, presentes en el poema, muestran la segunda alternancia: sandia 750a; sandio 976a, 99li, y 1387d. Si asi (y siempre en la hipótesis de que hubiera corrupción en el verso), sería razón justificada; aunque todavía insuficiente para no admitir que la forma sendia pudiera haber sido original de Juan Ruiz.
} 
da desfiguración del término recibido. La praxis editorial aplicada a los viejos textos manuscritos, como es sabido, tiende en lo posible a respetar al máximo los grafemas consonantes de las lecciones recibidas supuestamente deturpadas (conformatio textus), en virtud del criterio de probabilidad; puesto que, en verdad, es en los fonemas consonánticos (que aquéllos representan) donde se agarra con firmeza la estructura de la palabra. De ahí que, en la faena editorial, cuanto menos se dañe o altere la estructura consonántica de la lección manuscrita mayor verisimilitud envuelve a las propuestas enmiendas de tal lección; entiéndase ello como principio general. Cualquier cambio consonántico introducido en la palabra problemática requiere, sin duda, una más firme justificación para ponerlo en efecto que la alteración (o aun, incluso, la eliminación) de sus vocales. Ninguna extrañeza ocasiona la frecuente deformación vocálica que presentan los manuscritos medievales. Ella es natural, y comprensible: refleja en gran medida el estado de la lengua viva $y$, con mayor razón, la del escriba que traslada los textos, incluidos sus propios errores cometidos por descuido o ignorancia. La articulación de las vocales en el parlante requiere menos esfuerzo que la consonántica y, por ello, está sujeta a menor matización fónica; de donde el corrimiento del punto articulatorio de las mismas y, consecuentemente, la susodicha desfiguración o alteración vocálica que los escritos vernáculos reflejan, más o menos conformada a la norma común (cuando no equivocada).

Antes de exponer mi parecer definitivo del punto en cuestión, sirva la observación acabada de indicar como base justificatoria parcial a la sugerencia que presentamos de seguidas, a título sólo de simple hipótesis disquisicional, como alternante posible de la comentada de Lida. Se reduce, en breve, a indicar que - caso de que el locus estuviera viciado, valga la insistencia - parece sería más pertinente la rectificación del sentia manuscrito a enatía; no a sendía/sandia. Razonaré el porqué:

$1^{\circ}$. Siempre sin salir del plano hipotético de que sentia fuera error de transcripción: Paradinas pudo haberse encontrado en el locus con una palabra ya deturpada y, por ello dificil de interpretar, a saber: senatia. Razón por la que eliminaría su - $a$ - interna para darla algún sentido significativo: sentia; corrompiendo todavía más así la palabra supuestamente original ruiciana. Pero cabe suponer también, y acaso con mayor oportunidad, que sentia constara ya en el subarquetipo de $S$ y que el escriba responsable del mismo hubiera sido, quien dejara de copiar indebidamente la dicha - $a$ - entre $n$ y $t$ (existente en la lección del modelo $X$ que trasladaba) al no entenderla, bien por estar ella mal formada, bien porque, en su memorización del verso (esto es, leído él previamente y retenido en la memoria para, de inmediato, ser copiado en el nuevo folio) hubiera con- 
fundido la propiedad de las palabras, extendiendo la sonoridad de la $-s$ del inmediato mas ( $\mathrm{y}$, por tanto, la letra que representa al dicho fonema) a la inicial de la forma discutida: mas $<s>e n[a]$ tia; es éste fenómeno ocurrente muy típico, constante por doquier en los textos manuscritos antiguos, incluso en otros lugares del $L B A^{5}$.

$2^{\circ}$. Enatia es voz que nos parece tan adecuada al contexto como sandia (seguimos en el plano hipotético de que el locus precisase enmienda). La significación más común de sandio es la de 'flojo de mente', 'tonto' (aplicable en todos sus matices); de ahí que valga también, por extensión semántica, para referir el vocablo al 'casquivano' o 'loquillo'. Enatío (quizá formación semiculta derivada de *ex-natum: *ex-nativum > enatio 'nacido prematuramente', como su antónimo tal vez lo sea de natum, a partir de su adjetivo verbal nativus; si es que no formación directa arrancada del mismo natio ${ }^{6}$ ) en su origen equivalía a 'mal nacido'; de donde, generalizado, 'deforme', 'feo' -acepción muy corriente en los textos antiguos-, 'loco', 'de mala casta' etc., sentidos que Corominas también le aplica, por extensión, al suponer él la voz procedente del adjetivo inaptus (lat. clás., ineptus: 'inepto', 'necio'). Como de 'mala casta' hay que entender la voz, p. ej., en la cita aportada en el $D C E$ : «[los] Cenófalos, que es gente muy fea, e muy enatía e muy departida de nosotros» (Hist. Troyana, [Madrid, 1934], pág. 141); 'disparatado, loco' es la acepción que lleva el femenino enacia ( $₫$ c , lectura deficiente?) en «[cuando vio donna Termuth] en el ninno que la su criança que se non fazie cosa enacia, plogol» (GE, 1, 302a), y en el Picatrix consta el vocablo con el significado de 'alocado', 'ligero de cascos': «en la terçera faz de leon sube omne que á la figura cuemo los negros, mui feo, e muy enatio, e es mucha lazeria, et de mucho cuydado" (Madison, 1987 , fol. 10r), etc.

\footnotetext{
${ }^{5}$ Por ejemplo, en $455 \mathrm{aS}$ conbardo (incorrectamente leido por los editores covardo, llevándoles así a error), rectificado es con bardo; en $414 c G$ laenrarie, que rectificado es $l a$ en [t]rarie; en $821 \mathrm{G} / \mathrm{S}$ en cabo/encabo, que debe rectificarse a encobo; en $1369 \mathrm{cTS}$ enplea, que corregido es en prea. Justifico estas cuatro lecturas en mi trabajo "Observaciones paleográficas en los manuscritos del Libro de Buen Amors, RFE, LXXX, 2000, págs. 69-87, etc.

'El significado primario 'nacido bien, normal, a su tiempo' prácticamente está perdido; pero se deduce de su noción adjetival 'hermoso [fisicamente]' que, aunque poco corriente en los textos viejos, se deja ver, p. ej., en el mismo $L B A$ interpelándose al Amor: «Ansi muchas fermosas contigo se enartan; / con quien se les antoja, con aquél se apartan: / quier feo, quier natio, aguisado non catan", 403abc.; véase también Francisco de las Natas, Comedia Tidiana, v. 912. Acaso desplazara al adjetivo el predominio del uso de la voz como sustantivo ('nacimiento'), el que se ve repetidamente utilizado en las Partidas, según ya djce Corominas, en las Eglogas de Juan del Encina (XXX, v. 87: 'raza', 'limpieza de linaje'; XXXI, v. 228 'tipo de nacimiento', etc.), alguna ocurrencia en la Crón. General, etc.
} 
Juan Ruiz utiliza el adjetivo en 402c para expresar la misma idea que nos ocupa ('ligero de cascos', 'alocado'; así, creo, debe interpretarse en tal verso, aunque los editores prefieren explicarlo en él como 'feo') aplicándoselo al lobo y echando mano del tradicional proverbio:

fazes con tu grand fuego como faze la loba: al más astroso lobo, al enatio, ajoba.

Por tanto, sólo en razón de tratar (y mantener) la lección recibida con el menor deterioro posible habría sido solución más consecuente (en el plano hipotético de que venimos hablando) la aplicación, como enmienda, si no de sendia, la de la sugerencia alternante enatia; una y otra preferibles a la que viene incorporándose en el texto de casi todas las ediciones académicas desde 1964 (ed. de Chiarini).

Pero, irealmente precisa enmienda alguna la lección manuscrita en cuestión? Nosotros no lo creemos en absoluto. En el verso, y en su contexto, encaja perfectamente sentia: ello requiere sólo el interpretar el verso en la forma debida; esto es, en modo alguno refiriendo el sentía al yo parlante, como propuso Cejador («más sentía, todavía pensaba y juzgaba más»; así explicó), sino a la joven otra. Glosado el verso así, él recibe el siguiente sentido, hasta ahora desatendido por la Crítica: 'puse mi mirada en otra joven, ciertamente no santa [inclúyase en el vocablo lo que el lector quiera imaginar], pero tenía corazón, le bullía la sangre..., sabía amar intensamente'. Que a eso alcanza - y con plena adecuidad - el sentia comentado, al menos a nuestro juicio.

La lección debe ser respetada en toda su integridad; tiene todo el corte de ser original de Juan Ruiz. $Y$ así, no hay razón para rechazarla como espúrea.

E, porque yo non podía con ella ansí fablar, puse por mi mensajero, coidando recabdar, a un mi conpañero; sópome el clavo echar: él comió la vïanda e a mí fazié rumiar. estr. 113

Tres detalles de esta cuarteta quisiera poner a juicio del estudioso, dado que no estoy conforme con la interpretación que se les viene dando por los críticos y editores desde 1913, creo, sin excepción alguna. Son ciertamente insignificantes; pero, no obstante ello, conviene airearlos:

El primero y segundo, pues ambos están relacionados estrechamente, tienen que ver con la partícula $m i$ del segundo verso, interpretada como 
adjetivo posesivo por los editores; lo cual ha llevado a los mismos a dar a recabdar el sentido concreto de 'sacar provecho' ". Así, implícitamente, lo insinúa Corominas al discutir el punto $\mathrm{y}$, con mayor claridad, Joset ( “'lograr'», en el sentido de 'lograr provecho para si') y Blecua. Tal es la razón de haber incluido todos ellos entre comas —obviamente, equivalentes a paréntesis en el verso- el coidando recabdar. A la oración de gerundio así entendida —esto es, disociándosela de conpañero - se le da un matiz final terminativo en ella misma: 'teniendo cuidado de sacar yo provecho [de mi acción: la del poner mensajero]'; y a un mi conpañero se le interpreta como el objeto directo de puse. Tal construcción de estos tres hemistiquios, si bien defendible, la tengo por retorcida y con una acepción de recabdar menos usada en el tiempo.

Nuestro parecer, acordado al de Sánchez/Janer, es el siguiente: $1^{\circ}$, que $m i$ es realmente un pronombre personal ('puse mensajero para mí', 'en mi lugar'; si se quiere, entiéndase el por mí como causal o final: 'a causa de mí', o 'para/en beneficio mio'), y $2^{\circ}$, que recabdar lleva impresa la acepción más común y general de 'conseguir, lograr', sin mayor precisión o limitación de concepto; esto es, la que muestra por doquier el articulado de las Partidas y, repetidamente, el $L B A$ : «trabajan e afanan mucho, sin medida, / e los más non recabdan la cosa querida» $152 \mathrm{~cd}$; «si tú fasta agora cosa non recabdaste / de dueñas..., / tórnate a tu culpa...», 426a-c; «recabdat lo que queredes, non vos tengan por çestilla», 870c. Así interpretado el pasaje, a un mi conpañero resulta ser el término objeto de recabdar (no el de puse); por lo que sobra la coma tras el tal verbo. $Y$ el sentido de estas frases, según las entiendo, es como sigue: 'Puse, en vez de mí, un mensajero, procurando conseguir para ello un buen amigo mío'. Adviértase que el adjetivo posesivo $m i$ del verso tercero no está caprichosamente elegido: lleva su buena miga unido a un conpañero; puesto que todo ello implica 'un amigo de confianza', 'uno que me era fiel', aunque luego le saliera rana al protagonista del cuento, como tantas veces sucede en el juego del amor y en el de tantas otras relaciones humanas.

Entremos en el tercer detalle aludido: el clavo echar.

La acepción de 'engañar' que se le aplica a esta frase del v. $113 \mathrm{c}$ viene siendo aceptada unánimemente por los críticos interesados en el $L B A$ desde que se propuso en 1913 por Cejador. Ella pudiera ser la interpretación debida (aunque quien aquí escribe no la tenga por tal), ya que encaja sin es-

\footnotetext{
${ }^{7}$ Eso así, pero tal vez también debiơo a haber aceptado la interpretación de Cejador, quien, aun omitiendo incorrectamente la dicha partícula, interpreta el recabdar también como 'ganar', 'tener por suyo', y, por tanto, la frase de gerundio, encerrada entre comas, como la entienden los editores sucesivos, según indicamos en texto.
} 
tridencias en el contexto donde aparece. La insatisfacción o contrariedad que la misma nos levanta radica, en gran medida $-\mathrm{y}$ no con exclusividad-, en el hecho de no haber dado todavía con otro ejemplo de echar el clavo con tal significado en los textos vernáculos castellanos; las citas aportadas para defender tal noción son todas ellas tardias: F. de Figueroa (1600), S. de Covarrubias (1611), G. de Correas (1627), A. Moreto (1638), etc. Claro está que la expresión del $L B A$, en cierto modo, aboca a tal idea; pero, a mi parecer, sólo a través de un concepto más preciso y directo de la misma, utilizado intencionada y simbólicamente por ese observador alerta de la realidad en torno que era Juan Ruiz. He aquí tres maneras posibles de entender el interesante punto, echando mano de la metáfora concreta y exprimiendo el análisis de la frase hasta donde da de sí:

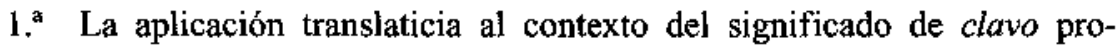
pio del vocabulario de las aves de cetrería: una especie de divieso, con la cabeza semejante a la de un clavo, que a'estas aves les sale en sus garras y que, al parecer, es extremadamente doloroso ${ }^{8}$. De donde sópome el clavo echar equivaldría aqui: A) a 'se dio mañas para ponerme en mi corazón un gran dolor', aludiendo al desleal proceder del amigo: el haberle arrebatado su amor traicioneramente; B) a 'se las ingenió para pararme los pies' con el dolor de su infame acción (el indicado clavo simbólico): como se ve, una ligera variante de la anterior. Lo que en ambos casos cabe traducir (imagen desnudada) por 'supo engañarme'. La objeción que podría levantarse a esta bimembre idea es la de que al clavo enfermedad avícola no le va bien el verbo echar, ya que la tal dolencia no se echa, sino que aparece o sale. Valga replicar que ello no resulta ser argumento firme si se tiene en cuenta que el pasaje ruiciano evidentemente viene expresado todo él en un plano simbólico incuestionable; en parecido sentido traslaticio dice el Arcipreste, echando mano ahora de una prosopopeya, tomáronlo adivas [al caballo], 302c.

2. 'Sópome el clavo echar: 'súpome frenar en seco', 'se amañó para pararme los pies': de donde 'súpome ganarme la partida' $y$, si se quiere -pues, como digo, el simbolismo acaba ciertamente en ello-- 'súpome engañar' en el sentido recto. La base de tal idea está en que, en el tiempo de Juan Ruiz, echar el clavo significaba, en su noción primaria, exactamente eso: 'frenar'. El sistema que las carretas medievales tenían para frenar era la

\footnotetext{
${ }^{8}$ «Es esta dolencia de tal manera en las plantas o palmas de las manos de los halcones, que les salen unas postillas o costras muy fixadas en aquel lugar y la figura dello es a manera de cabezas de clavo. Hínchanseles las manos y árdenles, y algunas veces se les paran algo coloradas y cáusanles tanto dolor que non pueden sostenerse sobre ellas», Fadrique de Zúñiga, L. de Cetrería (ed. Madrid, 1953), pág. 220. Véase también P. López de Ayala, L. de la caza (ed. Madrid, 1959), págs. 89, 159, 161, etc.
} 
aplicación de una barra de hierro o, más común, la de un palo largo (el clavo o clavija) a la madera o zapateta (sortija la Ilama fray Diego de Valencia) que envolvía una sección del eje de las ruedas, las que, por supuesto, iban fijas al eje y rodando con él, tal como todavía ruedan las carretas gallegas, aunque éstas no llevan freno. Y la expresión normal para 'frenar' era echar o firmar ('fijar', 'afirmar', 'asegurar') el clavo, como para 'quitar o retirar el freno' era la de tirar ('re-tirar', 'quitar') o soltar el clavo. Algunos ejemplos textuales al efecto, tomados del Cancionero de Baena (1464):

Buelta es la rueda que andava [en] desuso, con grant pesadumbre quebró la sortija, rendióse el exe, soltó la clavija, cayó el carretero la cabeça ayuso...

\section{8: $1-4$.}

Doze vezes faze buelta

esta rueda cada'l día,

e non çessa todavía

en peligros muy embuelta;

quando la clavija suelta

assí mueve su espera ['esfera']

que quien más merçed espera

ésse falla más rebuelta ['problemas']

515: 1-8.

Tiren el clavo e ande la rueda,

que ya su firmeza ['frenada': sustantivo] non es razonable.

547: $1-2$.

Non ay braço tan luengo que pueda alcançar tan alto nin mano bastable a tirar el clavo por que ande la rueda, sinon El que la fizo, que non es palpable.

548: $1-4$.

Y, de aquí también el simbolismo de la frase "echar uno un clavo a la rueda de la fortuna", aportada por el Thesoro de la lengua y recogida en el Diccionario de la RAE y que repetidamente vemos también en el Canc. de Baena: «...será nesçesario el clavo firmar / assí que la espera ['esfera'] non pueda rodar, / çessando las cosas en su duración», 278: 36-38; «quando fuere dado el vuelco a la rueda [de la Fortuna] / e fuere tirado del exe el clavo, / allá será manso quien antes fue bravo...», 292:17-19.

3.' Sópome el clavo echar: 'supo sazonarme el plato', 'me la puso bien en sazón [a la jóven rondada]', 'me la preparó bien'... (dicho con fuerte ironía); y sigue: 'pero él se comió la vianda y a mí...', etc. Bien 
manifiesto está que clavo puede significar cabalmente aquí «el capullo seco de la flor del clavero..., de olor muy arómático y agradable y sabor acre y picante» (Dic. de la RAE); esto es, la especia tan intensamente sabrosa y tan típica de los guisos castellanos, al menos, de los de La Alcarria. La juguetona apicantada alegoría banquetil de los versos finales no puede estar más a tono con el episodio narrado y su implícita moraleja: echar el clavo (al 'guiso'), comer, vianda y (¡cómo no!, aunque Cejador desechara la acepción directa del verbo, usada traslaticiamente) rumiar ${ }^{9}$; pero sin negarle a este verbo también la noción metafórica concomitante de 'repensar, considerar despacio'; doble sentido que creo fue también intencionado de Juan Ruiz, como asimismo lo siente Joset, aunque sin haber llegado él a comprender el alcance simbólico del pasaje todo como aquí se propone.

Recapitulando y, como conclusión del tema, no puedo decir cuál de las tres propuestas sería la que el Arcipreste, burlonamente sagaz, tuviera en el pensamiento y plasmara en su $L B A^{10}$. Las tres muestran suficientes méritos y válidos puntos de apoyo para admitírselas como salidas de su pluma; pero tiendo a inclinarme por una de las dos últimas y, acaso con alguna mayor convicción hacia la tercera, por considerarla como más a tono con el modo deliciosamente juguetón de decir o narrar Juan Ruiz esos sus sabrosos retraeres y fábulas ${ }^{11}$.

\footnotetext{
${ }^{9}$ Me refiero al mismo sentido metafórico (estrechamente cercano al recto del verbo) que Juan Ruiz utiliza en $118 \mathrm{c}$ : «...e fizose de la Cruz privado: / a mí dio rumiar salvado, / él comió el pan más duz»».

${ }_{10}$ Intencionadamente silencio aquí, como despropósito violento, el sentido sexual (unido al de 'escarnecer') que quieren ver Claude Allègre y René Cotrait en el echar el clavo, en lo que ellos llaman plano pornográfico dentro de una apariencia inocente: «Foisonnement de sers et niveaux de lecture dans la 'trova cazurra' de Juan Ruizs, $R L R, \operatorname{LXXX}, 1973$, págs. 5794 , ad hoc, pág. 74 .

${ }^{11}$ Incidentalmente, la derivación sernántica echar el clavo $\rightarrow$ engañar la explica Covarrubias como arrancada de las trampas o engaños que los herreros, dice, solían hacer a sus clientes al herrar las caballerías, poniendo a éstas malos clavos por buenos. Tal vez fuera mejor explicación para el cambio nocional el partir del clavo especia, que hace dar sabor nuevo y más palatable a lo que to tiene malo o desabrido, de donde cosa con gusto no propio $\rightarrow$ cosa desvirtuada o engañosa $\rightarrow$ engaño. La cita de La Pícara Justina, aportada por Joset para este lugar, refuerza la dicha suposición: «echar mucho clavo 'engañar"», (ed. Madrid, 1912 , t. 1, 87).
} 